\title{
CARACTERIZAÇÃO FÍSICA E SÓCIO-AMBIENTAL DA ATIVIDADE DE PISCICULTURA: CASO DA BACIA HIDROGRÁFICA DO RIO CUBATÃO DO NORTE - SC - BRASIL
}

\author{
PHYSICAL, SOCIAL AND ENVIRONMENTAL \\ CHARACTERIZATION OF PISCICULTURE ACTIVITY: \\ THE CASE OF THE HYDROGRAPHIC BASIN OF THE \\ CUBATÃO DO NORTE RIVER - SC - BRAZIL
}

\author{
Aquino, P. Q ${ }^{1}$; Gonçalves, M. L. ${ }^{2}$ \\ ${ }^{1,2}$ Universidade da Região de Joinville - UNIVILLE \\ Campus Universitário s/n. - Bom Retiro - Joinville/SC - CEP: 89.201-972 \\ e-mail: paula.queiroz@univille.net
}

\section{RESUMO}

Este trabalho objetiva avaliar os impactos sócio-econômicos e ambientais causados pela piscicultura na Bacia Hidrográfica do Rio Cubatão do Norte (BHRCN), localizada na região Norte do Estado de Santa Catarina. O trabalho de campo foi realizado através de visitas aos locais onde a piscicultura é praticada, sendo avaliada a existência de licenças ambientais e projetos de construção dos tanques, o tipo de solo onde são encontradas as instalações, o ganho econômico da atividade, identificação dos peixes criados na região e outros, através da aplicação de um questionário durante o primeiro semestre de 2005. Os resultados foram obtidos em 19 das 26 propriedades visitadas com tanques de peixe na área da BHRCN. No que diz respeito à obtenção de licença ambiental, 68,4\% dos entrevistados afirmaram não ter ou não saber de sua existência, assim como $63,16 \%$ não tiveram ou não sabem da existência do projeto de construção dos seus tanques, o que pode implicar em severos impactos ambientais na região. Observou-se que $42,1 \%$ das propriedades apresentam solo pedregoso, que é inadequado à implantação de tanques de peixe, uma vez que este facilita a infiltração da água no solo. Percebeu-se que 47,4\% dos tanques de peixes foram construídos para consumo na propriedade, sem interesse comercial pela atividade. Diversos tipos de peixes foram encontrados nas propriedades, tais como tilápia (Oreochromis spp), carpa (Cyprinus spp), traíra (Hoplias malabaricus) e pacu (Piaractus mesopotamicus). A partir dos resultados conclui-se que a falta de regulamentação dos tanques e a carência de informação por 
parte dos piscicultores podem gerar impactos nas águas superficiais e subterrâneas da região.

Palavras-chaves: Piscicultura. Tanques de peixe. Bacia hidrográfica. Rio Cubatão do Norte. Impactos ambientais.

\begin{abstract}
The objective of the present article is to evaluate socioeconomic and environmental impacts caused by fish culture in the Cubatão do Norte River Hydrographic Basin (CNRHB), located in the north of the state of Santa Catarina, Brazil. The fieldwork consisted of visits to the places where fish culture is practiced and application of a questionnaire during the first semester of 2005; the existence of environmental licenses and projects was evaluated as well as the type of soil where the fishponds are located, the owners' economic profit, identification of cultivated species in the region and others. Results were obtained in 19 of the 26 properties with fishponds visited in the CNRHB area. With respect to environmental licenses, $68.4 \%$ of respondents claimed they were unaware of their existence, and $63.16 \%$ stated they did not have or did not know of the existence of pond construction projects, which can lead to severe environmental impacts in the region. It was observed that $42.1 \%$ of the properties had rocky soil which is inadequate for the implantation of fishponds since they facilitate infiltration of water into the ground. It was noted that $47.4 \%$ of the fishponds had been constructed for consumption on the property itself with no commercial interest for the activity. Many types of fish were found on the properties, such as tilapia (Oreochromis spp), carp (Cyprinus spp), traíra (Hoplias malabaricus) and pacu (Piaractus mesopotamicus). From the results it can be concluded that the lack of regulation of the tanks and the lack of information on the part of the fish culturists can cause impacts in superficial and underground waters of the region.
\end{abstract}

Key words: Pisciculture. Fish Tanks. Hydrographic Basin, Cubatão do Norte River, Environmental Impacts.

\title{
1. INTRODUÇÃO
}

A pesca indiscriminada mata e desperdiça entre 18 e 40 milhões de toneladas de peixes não-comerciais todos os anos, representando cerca de um terço de toda pesca mundial. Nos últimos 20 anos, a pesca em excesso e no período de desova foram responsáveis pela redução em mais de $80 \%$ de espécies como peixe-espada, atum e vários tipos de tubarões. Segundo Sea Shepherd (2004), 70\% dos estoques comerciais de peixe no mundo estão esgotados, super explorados, extintos ou em processo de lenta recuperação. 
Além de apresentar maior produtividade em relação à pesca tradicional, a piscicultura (aqüicultura com o cultivo somente de peixes) evita com que os habitats naturais das espécies comerciais de peixe sejam super explorados, evitando assim um esgotamento precoce do número de indivíduos da espécie. Os produtores comercializam a produção na sua propriedade. Os peixes mais cultivados são a tilápia (Oreochromis spp.) e as carpas (Cyprinus spp.). A comercialização, quase sempre sem a presença de intermediários, favorece ao produtor a obtenção de preços justos pelo produto. O objetivo de quem conduz qualquer sistema de produção é o de obter lucros e que estes sejam atrativos a ponto de motivar os produtores a permanecerem na atividade. Adicionalmente, os novos tempos impõem novos desafios, um dos quais o da sustentabilidade ambiental (SOUZA FILHO et al, 2002).

Segundo Arana (1999), aqüicultura sustentável é a produção viável, durável e ética de organismos aquáticos, explorando e conservando os recursos naturais, com a finalidade de atender às essencialidades presentes e futuras de todos. Os piscicultores que objetivam unicamente o lucro seguem, no entanto de alguma forma, o neoliberalismo, que se preocupa apenas com a dimensão econômica, atitude que leva, em muitos casos, a desprezar ou deixar de lado as dimensões ambientais e sociais no processo do desenvolvimento da atividade.

Quanto à deterioração da água utilizada, Tomazelli Jr. e Casaca (1998) citam que o maior aporte tanto de nutrientes quanto de sedimentos ao meio ambiente se dá durante a dragagem para a despesca. Os nutrientes aportados como compostos de nitrogênio inorgânico (principalmente amônia total), matéria orgânica e outros poluentes em potencial, acumulam-se no fundo do viveiro durante o período de cultivo, podendo ser liberados ao meio ambiente durante as renovações de água e a drenagem para a despesca.

De acordo com Boyd (1992 apud ARANA, 1999), o fornecimento de alimento é o principal fator causador da deterioração da qualidade da água dos tanques e do acúmulo de orgânica no fundo. $\mathrm{O}$ alimento não consumido e as fezes dos peixes contribuem diretamente para a poluição dos tanques sob a forma de matéria orgânica.

As características do tanque tendem a flutuar durante o ano influenciadas pelas condições climáticas locais, sendo que em regiões tropicais as variações ao longo de 24 horas são mais intensas em relação às diferentes estações do ano. Em sistemas rasos artificiais, os fatores climáticos, como o vento, atuam de forma direta, sendo certamente um fator de constante desestabilização hidráulica (TAVARES e COLUS, 1995).

A piscicultura desportiva é praticada em diversos países e constitui uma valiosa fonte de renda para o produtor, contribuindo para o desenvolvimento do turismo rural. No Estado de Santa Catarina, esta atividade conhecida como "pesque-pague", vem se desenvolvendo rapidamente, assim como também em todo Brasil segundo Empresa de Pesquisa Agropecuária e Extensão Rural de Santa Catarina S.A. (EPAGRI, 1996). 
A maioria dos piscicultores é de pequenos produtores rurais que, além das atividades agrícolas normais, incluíram essa nova alternativa em seus estabelecimentos O sistema de produção que predomina no Estado de Santa Catarina é o semi-intensivo em poli cultivo. Este sistema trabalha com várias espécies de peixes em um mesmo viveiro, mas cada uma delas com hábitos alimentares diferentes das outras. Entre tipos de peixes mais utilizados destacam-se a carpa comum (Cyprinus sp.), a tilápia (Oreochromis sp.), a carpa capim (Ctenopharyngodon idella) e o bagre africano (Bagre sp.), sendo todas as espécies de águas mornas (TAGLIARI, 1999).

Este trabalho possui como objetivo geral avaliar os impactos sócio-econômicos e ambientais causados pela piscicultura realizada na Bacia Hidrográfica do Rio Cubatão do Norte (BHRCN), localizada na região Norte do estado de Santa Catarina. Como objetivos específicos têm-se: elaborar o cadastro dos tanques de peixes existentes na BHRCN (ano de construção, presença de projeto e licença, número de tanques, distância fossa-tanque), avaliar o ganho econômico da atividade, identificar os sistemas de manejo dos tanques de peixe (fonte de abastecimento dos tanques, canais de entrada e saída de água, profundidade dos tanques, existência de reservatórios de abastecimento e tanques de decantação, freqüência do esgotamento e tipo e freqüência da alimentação), efetuar a identificação de perfis do solo, identificar as espécies criadas e fazer levantamento da legislação vigente relacionada à atividade e verificar se esta vem sendo cumprida.

\section{METODOLOGIA}

O trabalho de campo foi realizado no primeiro semestre de 2005 através de visitas aos locais onde a piscicultura é praticada, verificando as instalações, o local e fazendo a aplicação de um questionário. Foram registradas as coordenadas Universal Transversal de Mercator (UTM) de todas as propriedades visitadas com o aparelho receptor do Sistema de Posicionamento Global - GPS, marca Garmin GPS III+. Em seguida foi produzido um mapa da localização das propriedades na área da BHRCN com o auxílio dos softwares CARTALINX e IDRISI32 utilizando-se as bases cartográficas São Miguel, Garuva, Jaraguá do Sul e Joinville do Instituto Brasileiro de Geografia e Estatística (IBGE) na escala 1:50.000. Os resultados dos questionários foram tabulados e analisados à luz da literatura na forma de gráficos.

\section{RESULTADOS E DISCUSSÕES}

Foram identificadas 26 propriedades com tanques de peixe cuja localização na BHRCN consta na Figura 1. Nesta observa-se que todas as propriedades se encontram próximo aos rios existentes na bacia. 


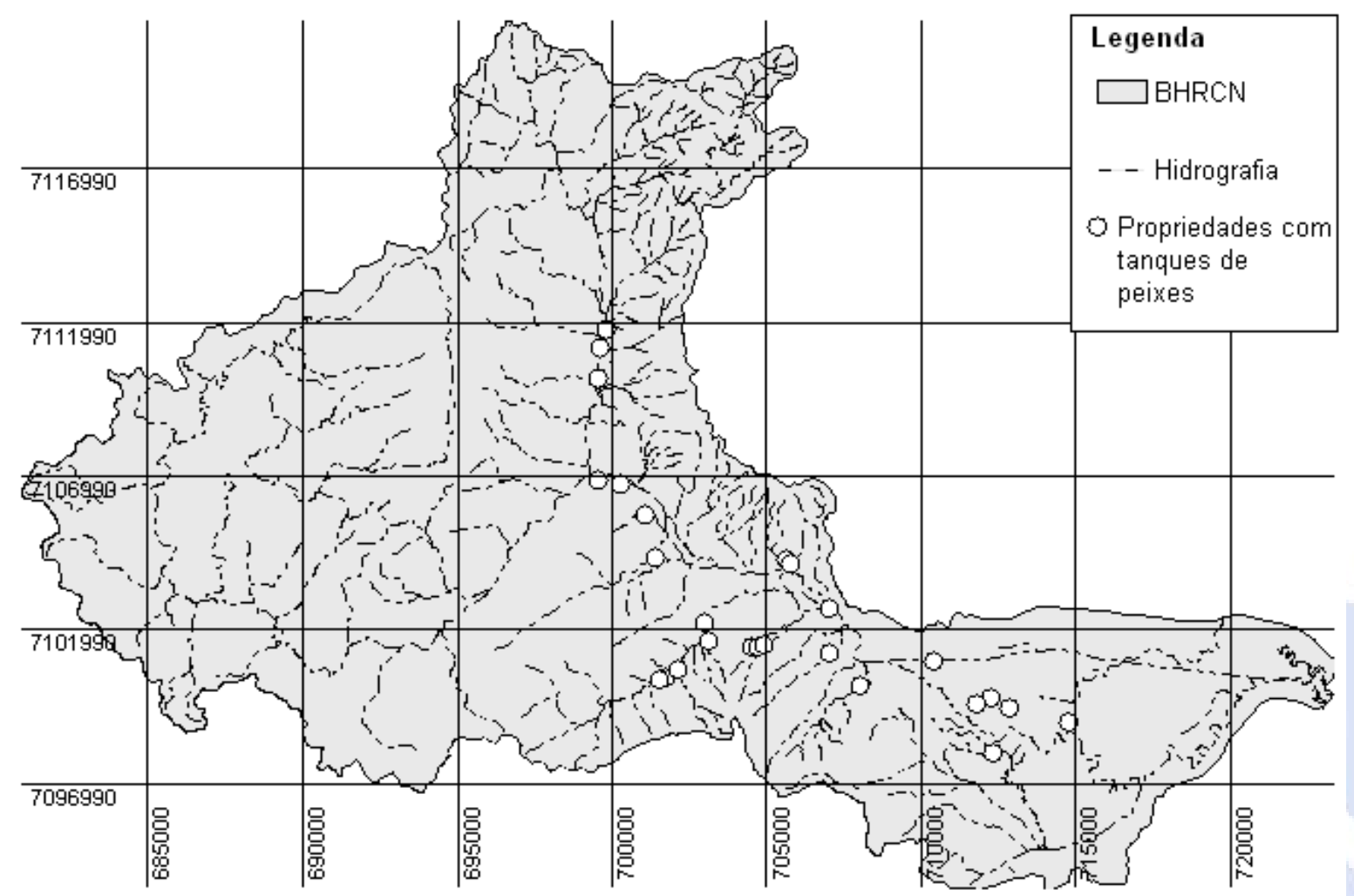

Figura 1. Mapa com a localização das propriedades com tanques de peixe na BHRCN.

Dentre as vinte e seis propriedades visitadas, foi obtido sucesso de entrevistas em dezenove, em decorrência do abandono dos tanques de peixe em três delas e a freqüente ausência dos proprietários nas outras.

Com relação ao ano de construção, nota-se que $26,3 \%$ dos tanques foram construídos na década de 80 e outros $36,8 \%$ entre os anos de 2000 e 2005, demonstrando um crescimento recente da atividade. Este fenômeno pode ser observado na Figura 2, que, assim como os demais gráficos, encontra-se anexo.

No que diz respeito à obtenção de licença, $68,4 \%$ dos entrevistados afirmaram não ter ou não saber de sua existência, assim como $63,16 \%$ não tiveram ou não sabem da existência de um projeto, o que pode implicar em severos impactos ambientais na região. Somente os tanques que foram construídos a partir do ano de 1999 obtiveram licenças; pois neste ano foi estabelecida a Portaria Intersetorial 01/1999 por parte da Secretaria de Estado do Desenvolvimento Urbano e Meio Ambiente (SDM) e da Fundação do Meio Ambiente (FATMA), na qual constam as diretrizes para o licenciamento da piscicultura e da aqüicultura. A Figura 3 demonstra a presença ou ausência de projeto e licença das propriedades. Comparando-se as colunas da figura em questão, observa-se que uma propriedade, apesar de ter projeto, não obteve a licença ambiental. A quantidade de proprietários que não tinham conhecimento sobre 
a presença de um projeto faz com que o número de propriedades sem licença torne-se proporcional às propriedades sem projeto.

De acordo com as normas recomendadas pela Fundação do Meio Ambiente (FATMA, 2005), a fossa, assim como a residência da propriedade, deve estar a uma distância mínima de $50 \mathrm{~m}$ para que não haja o risco de contaminação da água dos tanques. No entanto, $57,9 \%$ das propriedades apresentam fossa com distância inferior a $50 \mathrm{~m}$ das cavas, como mostra a Figura 4.

Quanto ao rendimento dos proprietários através da prática da piscicultura, percebeu-se que $47,4 \%$ dos tanques de peixes foram construídos para o consumo na propriedade, sem interesse comercial pela atividade. As propriedades cujas rendas não provinham exclusivamente da piscicultura consideram a atividade como complementar.

Complementando a atividade das propriedades, observa-se a presença de culturas agrícolas com o predomínio da banana e do aipim, como visto na Figura 5, seguido de hortas.

Segundo o Artigo $2^{\circ}$ da Lei 4.771 do Código Florestal (BRASIL, 1965), que determina que Área de Preservação Permanente (APP) é a área a uma distância mínima de trinta metros da margem de rios com até dez metros de largura composta pela mata ciliar. Somente uma propriedade possui um rio a quinze metros do tanque, ou seja, este está parcialmente dentro de uma APP (Figura 6).

Segundo Schmidt (1988), a melhor água para viveiros é a proveniente de um pequeno riacho. Não se deve utilizar a água de poços para o abastecimento da piscicultura, pois esta não apresenta plâncton. Apesar desta recomendação, a presente pesquisa constatou que $26,3 \%$ dos piscicultores usam água proveniente do lençol freático e $38 \%$ usam águas de nascentes, como visto na Figura 7.

Durante as entrevistas observou-se maior presença de canais de escoamento em relação aos canais de abastecimento, o que se dá pelo grande número de piscicultores que retiram água diretamente do lençol freático para o fornecimento dos tanques, técnica essa que não é recomendada em decorrência do baixo teor de oxigênio dissolvido das águas subterrâneas. Este fenômeno pode ser observado na Figura 8.

A FATMA (2005) recomendou uma profundidade mínima de $0,8 \mathrm{~m}$ e uma máxima $1 \mathrm{~m}$, sendo que nas regiões mais frias pode chegar a $2 \mathrm{~m}$ em um dos lados. Profundidades maiores são inúteis uma vez que o fundo do tanque não possui quantidade suficiente de oxigênio para o desenvolvimento da grande maioria dos peixes e podem até comprometer os recursos do lençol freático local. Tendo isto em vista, observou-se que $36,8 \%$ dos tanques possuem uma lâmina de água com profundidade maior do que a recomendada, o que pode interferir na dinâmica do lençol freático local.

A FATMA (2005) recomendou a construção de reservatório para a piscicultura como prevenção às épocas de estiagem, entretanto, $68,4 \%$ das propriedades não apresentam reservatório. 
Em nenhuma das propriedades foi encontrado tanque de decantação ou qualquer tipo de tratamento para a água da despesca, sendo esta mais uma ameaça à qualidade das águas dos rios receptores da água proveniente dos tanques de peixe.

A Figura 9 apresenta a freqüência com que é feito o esgotamento dos tanques, evento este que carrega a maior parte da matéria orgânica presente nos viveiros. Observou-se que $36,8 \%$ dos proprietários não possuem previsão da freqüência de limpeza dos tanques: só o fazem quando aparece a necessidade.

Alimentos suplementares, em formas de rações, são muito utilizados em piscicultura, embora pouca atenção tenha sido dada ao papel dos restos de alimentos e das fezes na qualidade da água. Existem evidências de que o acúmulo de material orgânico pode causar grandes alterações na água, o que afetaria o crescimento dos peixes (PINHEIRO e SANTOS, 1993). A gravidade deste problema pode variar de acordo com a freqüência com que são alimentados e a quantidade. A Figura 10 apresenta a freqüência com a qual são alimentados os peixes $(68,8 \%$ são alimentados diariamente). Já a Figura 11 mostra a quantidade de alimento que eles recebem por dia (36,7\% dos criadores disponibilizam até dez quilos de alimento por dia).

Percebeu-se que $42,1 \%$ dos proprietários consideram o solo pedregoso, o que é inadequado à implantação de tanques de peixe, uma vez que terrenos pedregosos facilitam a infiltração da água no solo. O tipo de solo mais adequado para tanques e viveiros é o que apresenta condições intermediárias entre o argiloso e o arenoso (PÁGINA DO PISCICULTOR, 2004).

Cerca de $87,7 \%$ dos proprietários utilizam a técnica do policultivo, ou seja, a criação de diversas espécies no mesmo tanque. Esta técnica é recomendada por Souza Filho et al (2002), que diz que esta medida reduz o desperdício da alimentação em decorrência das diferenças comportamentais dos peixes.

O desenvolvimento da piscicultura mundial e brasileira está baseado no cultivo de espécies normalmente exóticas ou alóctones a região de cultivo, provocando a contaminação do ambiente pela fuga acidental dos peixes cultivados ou até por parasitas (ZANIBONI FILHO et al, 1997).

O tipo de peixe encontrado nas propriedades predominantemente foi a tilápia (Oreochromis niloticus), seguido pela carpa capim (Ctenopharyngodon idella), traíra (Hoplias malabaricus) e pacu (Piaractus mesopotamicus). Subordinadamente, encontram-se carpa japonesa (Cyprinus $s p$.), pintado (Pseudoplatystoma $s p$.), bagre (Bagre sp.), carpa espelho (Cyprinus carpio specularis), dourado (Salminus sp.), jundiá (Ramdhia quelen), matrinxã (Brycon cephalus), carpa colorida (Cyprinus carpio), black bass (Micropterus salmoides), curimbatá (Prochilodus lineatus), cascudo (Hypostomus punctatus), lambari (Astianax sp.), carpa cabeça grande (Aristichithys nobilis), clárias (Clarias sp.), pirarucu (Arapaima sp.), cará (Gymnogeophagus sp.) e saguaru (Curimata sp.). A Figura 12 apresenta em quantas propriedades cada um destes tipos de peixe foram encontrados. 


\section{CONCLUSÕES}

O que pôde ser concluído a partir da realização deste trabalho é que a falta de regulamentação dos tanques e, principalmente, a carência de informação por parte dos piscicultores são as grandes responsáveis pelas irregularidades encontradas nos locais onde é praticada a piscicultura.

O objetivo de elaborar um cadastro dos tanques de peixe existentes na BHRCN foi alcançado parcialmente, pois, em decorrência do abandono de alguns tanques e do desconhecimento por parte dos entrevistados, não foi possível cadastrar todos dados questionados sobre todos os tanques. Foram identificados os sistemas de manejo e as espécies criadas.

Infelizmente, a legislação vigente relacionada à atividade ainda é precária e o cumprimento da normatização e licenciamento por parte dos órgãos ambientais ainda é incipiente.

\section{AGRADECIMENTOS}

À UNIVILLE pelo apoio através do programa de extensão universitária de Assessoria Técnica-Científica ao Comitê de Gerenciamento da Bacia Hidrográfica do Rio Cubatão do Norte. 


\section{ANEXO}

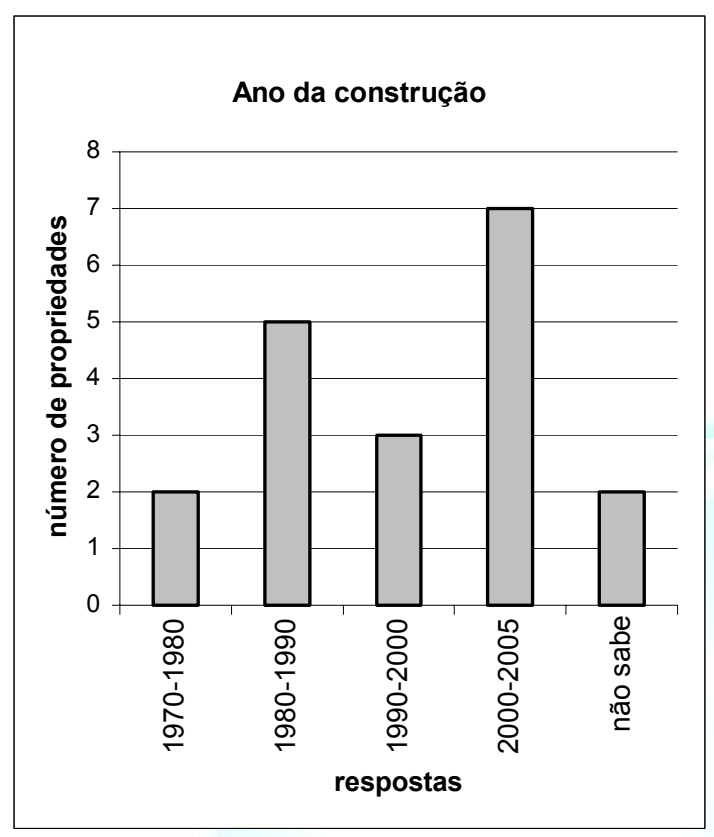

Figura 2. Anos de construção dos tanques.

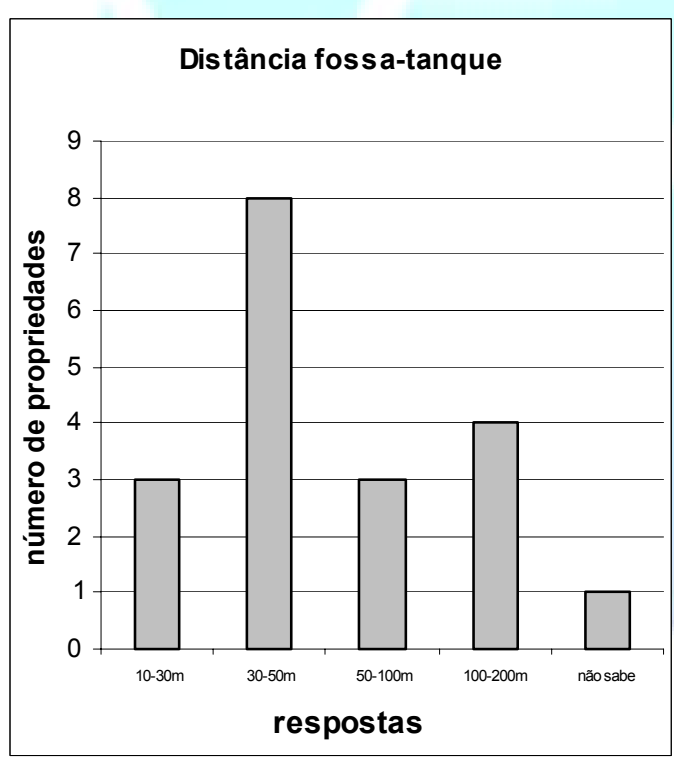

Figura 4. Distância entre a fossa e os tanques e peixe.

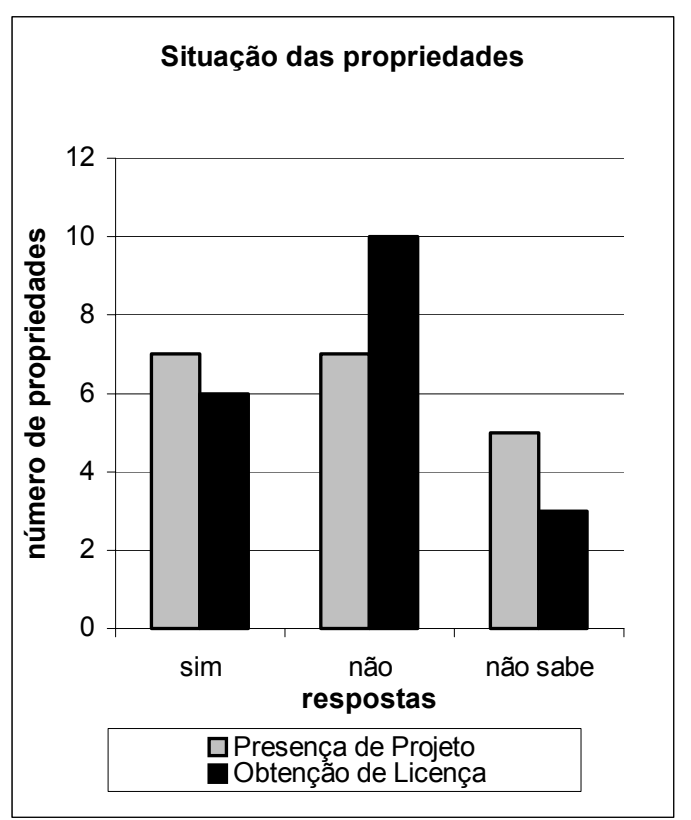

Figura 3. Número de propriedades que apresentam projeto e licença para atividade de piscicultura.

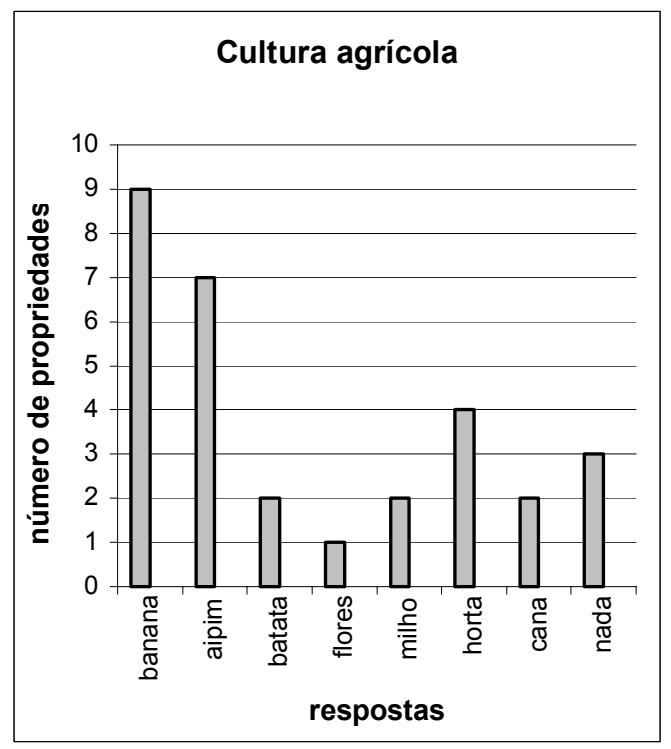

Figura 5. Atividades agrícolas presentes nas propriedades visitadas. 


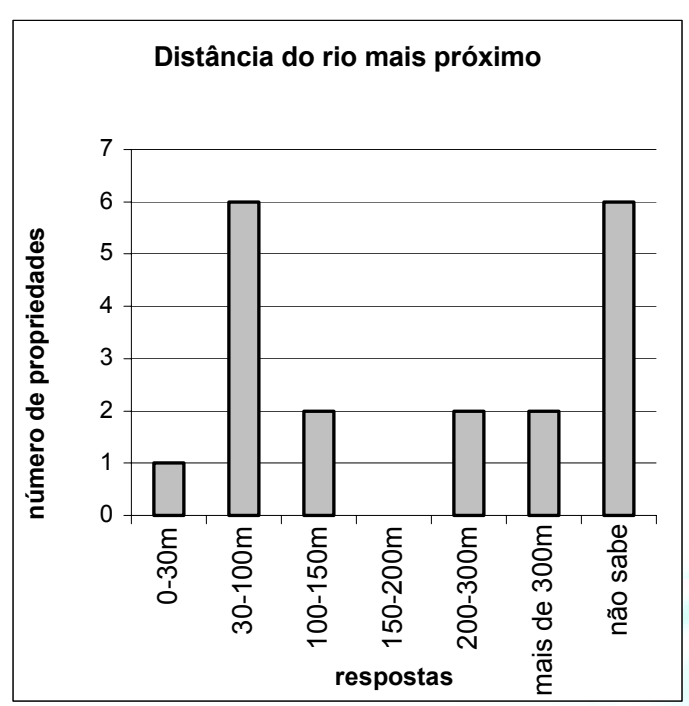

Figura 6. Distâncias entre os tanques e os rios mais próximos.

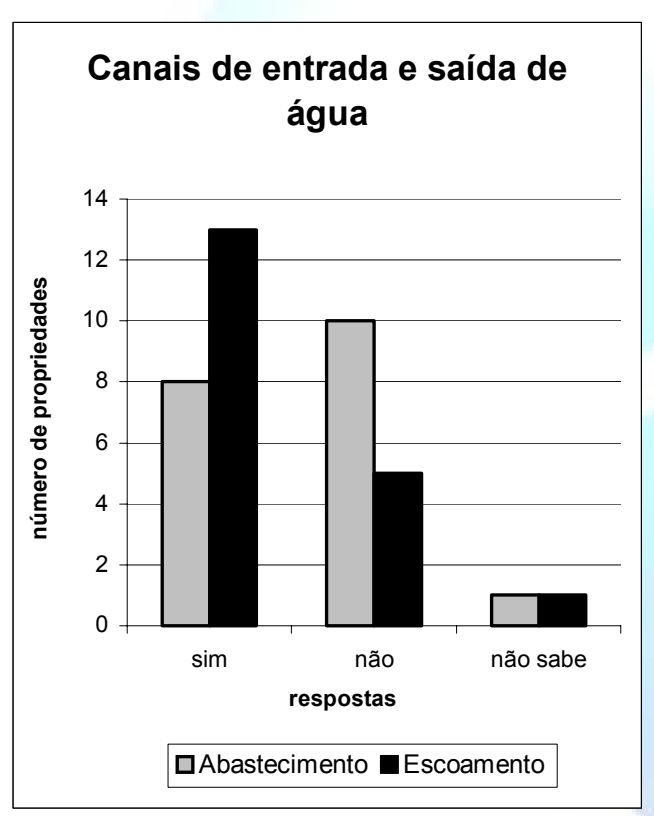

Figura 8. Presença de canais de abastecimento e escoamento de água.

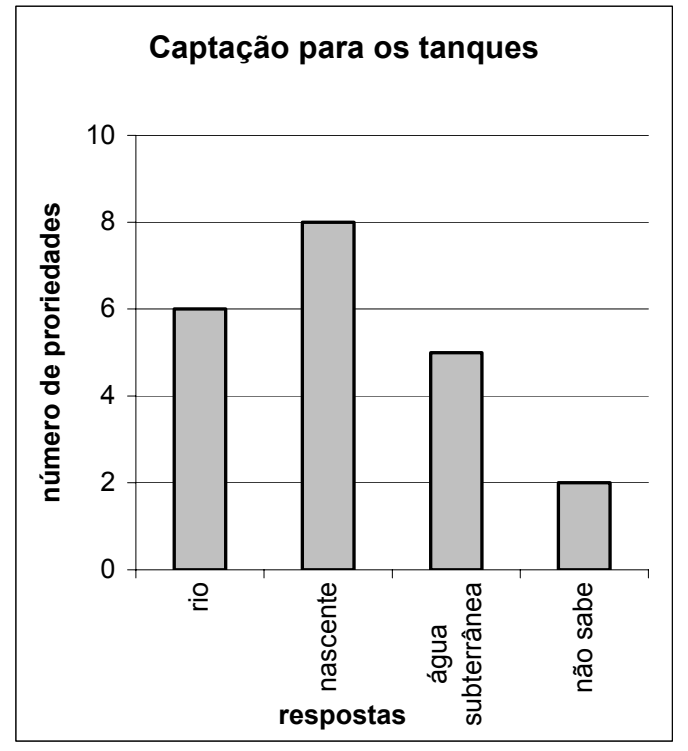

Figura 7. Origem da água que abastece os tanques

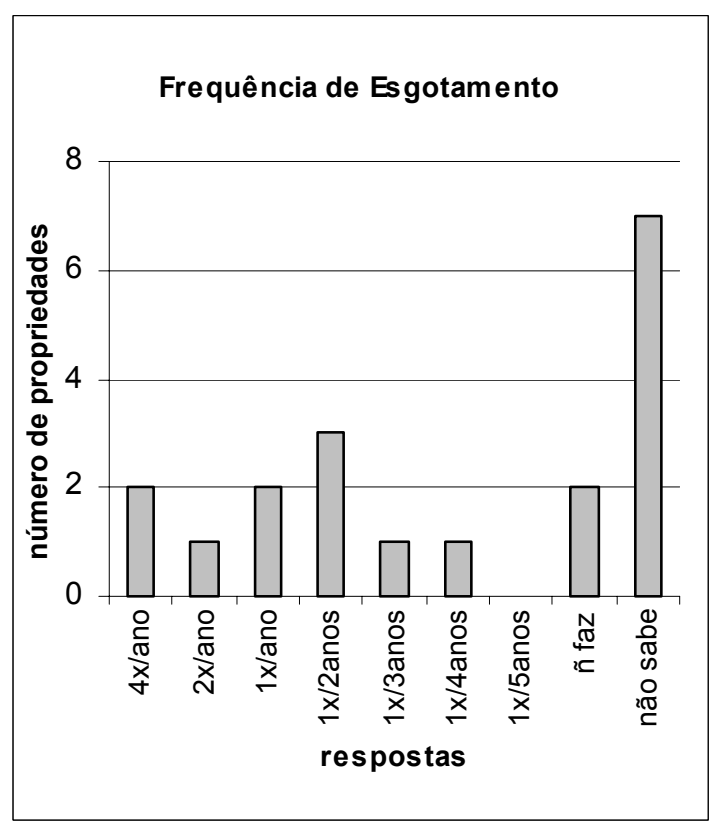

Figura 9. Freqüência com que é feito o esgotamento dos tanques. 


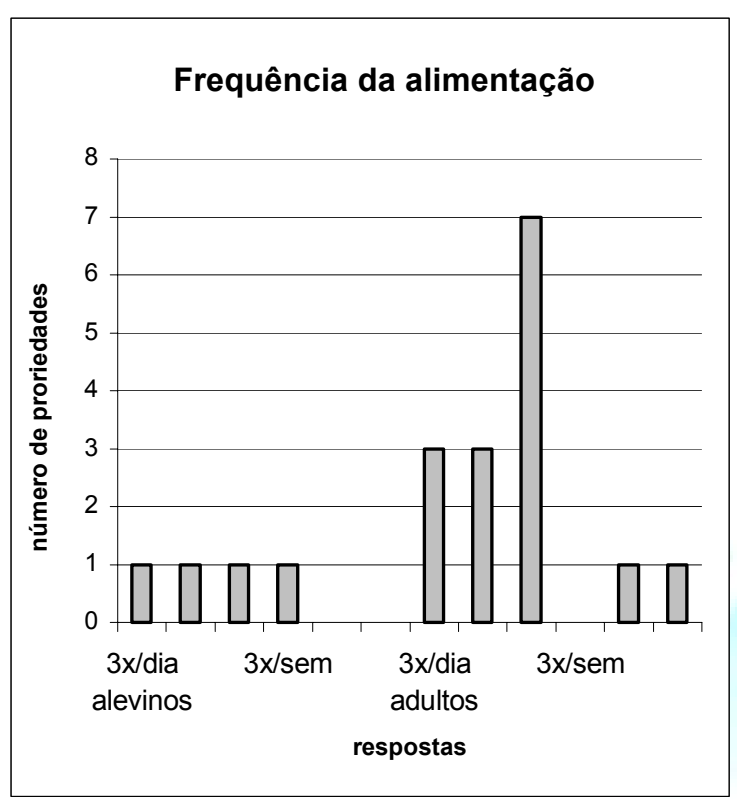

Figura 10. Freqüência da alimentação

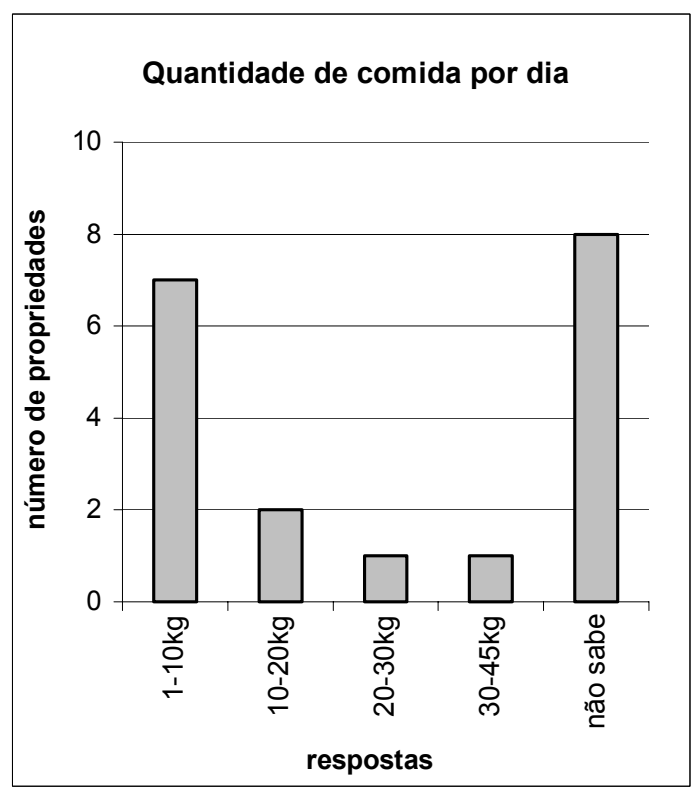

Figura 11. Quantidade de comida por dia

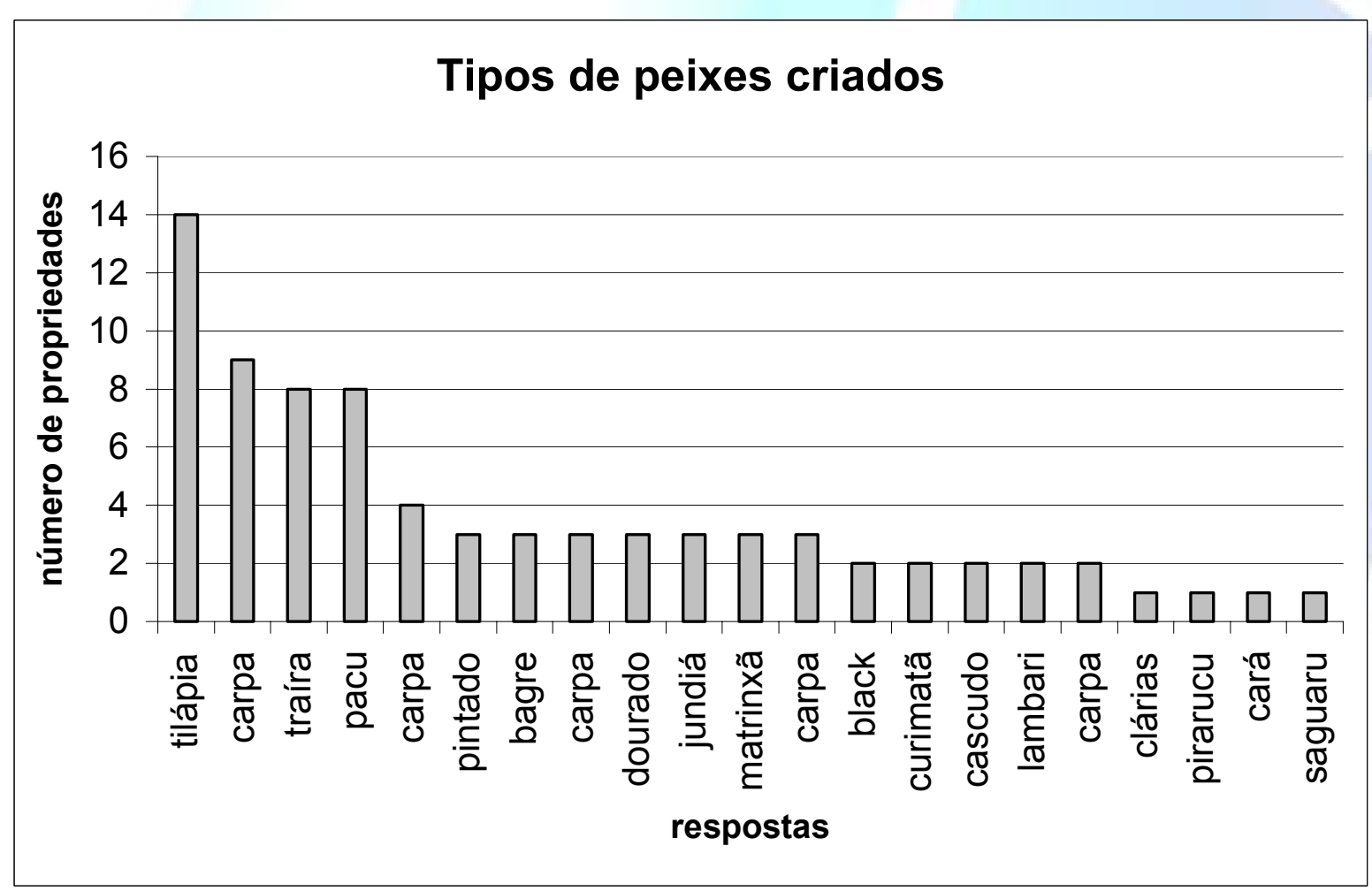

Figura 12. Principais tipos de peixes criados 


\begin{tabular}{|l|r|}
\hline Recebido em: 07/06/2006 & HOLOS Environment, v.7 n.1, 2007 - P. 41 \\
\hline Liberado para Publicação em: 12/06/2007 & ISSN:1519-8421 (CD-ROM) / ISSN:1519-8634 (ON-LINE) \\
\hline
\end{tabular}

\section{REFERÊNCIAS}

ARANA, L. V. Aqüicultura e desenvolvimento sustentável. Florianópolis: Editora da UFSC. 1999. 310 p.

BRASIL. Lei $\mathrm{n}^{0}$ 4.771, de 15 de setembro de 1965. Disponível em: http://www.planalto.gov.br/ccivil_03/Leis/L4771.htm. Acesso em: 7 jun. 2005.

EPAGRI - EMPRESA DE PESQUISA AGROPECUÁRIA E EXTENSÃO RURAL DE SANTA S.A. Curso Profissionalizante de Piscicultura de Água Doce. Florianópolis: EPAGRI. 1996.

FATMA - FUNDAÇÃO DO MEIO AMBIENTE. Piscicultura - Técnicas recomendadas. Disponível em: http://www.fatma.sc.gov.br. Acesso em: 6 mai. 2005.

PÁGINA DO PISCICULTOR. Apostila de Piscicultura. Disponível em: http://www.pescar.com.br/piscicultor/apostila.htm. Acesso em: 1 set. 2004.

PINHEIRO, P. E. C.; SANTOS, M. S. B. Effects of fish ration types on water quality. Ciência e Cultura, São Paulo, v. 45, n. 6, p. 399-402, , nov./dez. 1993.

SCHMIDT, A. A. Piscicultura - A fonte divertida de proteínas. São Paulo: Ícone Editora. 1988. 88 p.

SEA SHEPHERD. Agressões à vida marinha. Disponível em: http://www.seashepherd.org.br/agressoes.asp . Acesso em: 23 set. 2004.

SOUZA FILHO, J.; SCHAPPO, C.L.; TAMASSIA, S.T.; BHORCHARDT. Estudo da competitividade da piscicultura no Alto Vale do Itajaí. Florianópolis: CEPA/EPAGRI/ACAQ, 2002. 76 p.

TAGLIARI, P. S. Piscicultura atrai produtores rurais catarinenses. Agropecuária Catarinense, Florianópolis, v. 12, n. 3, p. 26-32, set. 1999.

TAVARES, L. H. S.; COLUS, D. S. O. Estudo da variação nictemeral em um viveiro de piscicultura no período de seca. Revista UNIMAR. Maringá. v.17 . n.2 .p. 225-236. ago. 1995.

TOMAZELLI JR., O.; CASACA, J. M. Avaliação dos efluentes da piscicultura durante a despesca. Agropecuária Catarinense. Florianópolis. v. 11 . n. 3 . 1998. p. 19-22. set. 1998.

ZANIBONI FILHO, E.; BARBOSA, N. D. C.; GONÇALVES, S. M. R. Caracterização e tratamento do efluente das estações de piscicultura. Revista UNIMAR, Maringá, v. 19, n. 2, p. 537-548, jun. 1997. 